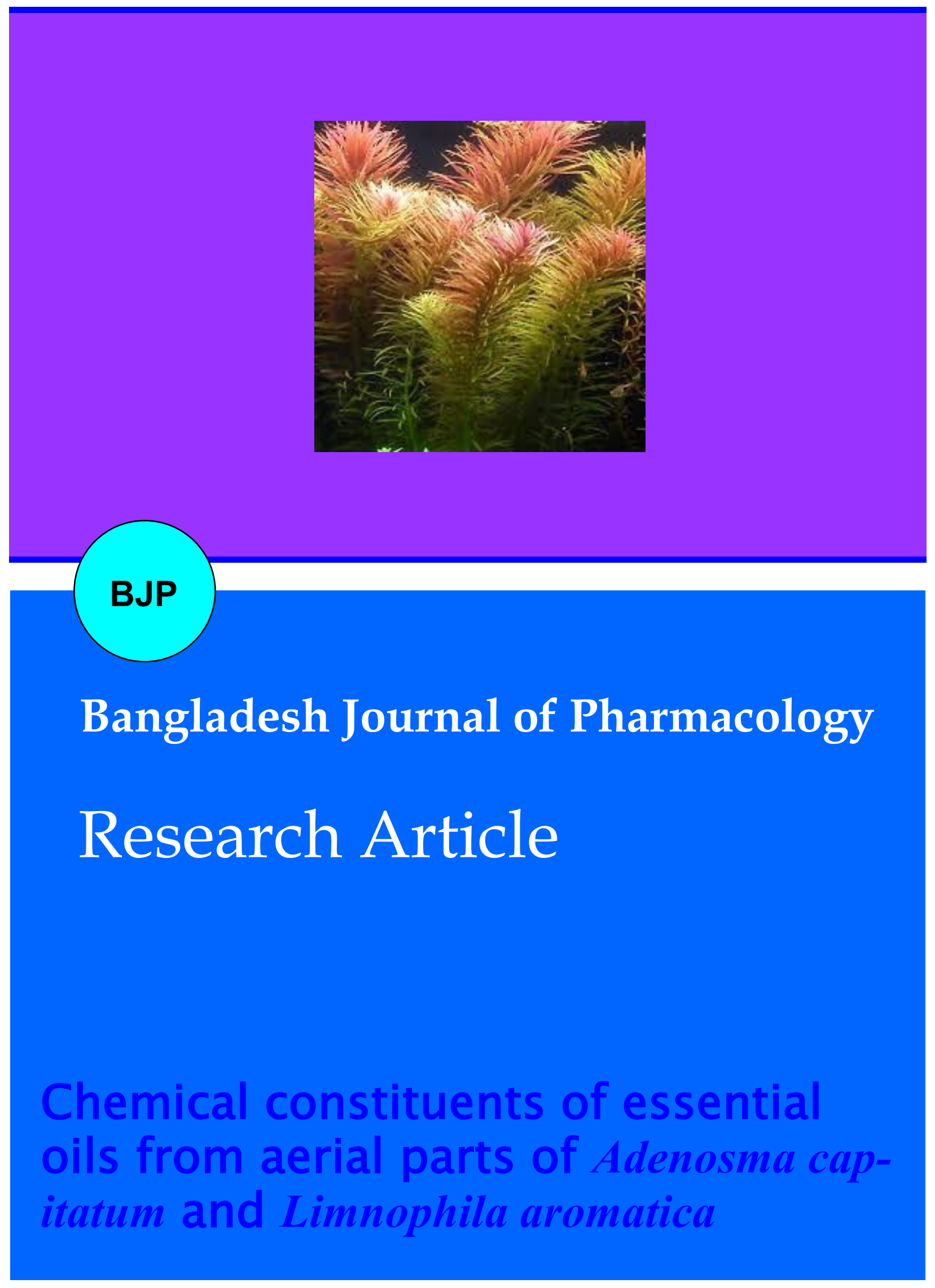


Abstracted/indexed in Academic Search Complete, Agroforestry Abstracts, Asia Journals Online, Bangladesh Journals Online, Biological Abstracts, BIOSIS Previews, CAB Abstracts, Current Abstracts, Directory of Open Access Journals, EMBASE/Excerpta Medica, Google Scholar, HINARI (WHO), International Pharmaceutical Abstracts, Open J-gate, Science Citation Index Expanded and Social Sciences Citation Index

\title{
Chemical constituents of essential oils from aerial parts of Adenosma capitatum and Limnophila aromatica
}

\author{
Md. Nazrul Islam Bhuiyan', Farhana Akter², Jasim Uddin Chowdhury' and Jaripa Begum. \\ ${ }^{1}$ BCSIR Laboratories, Chittagong; Chittagong Cantonment, Chittagong 4220, Bangladesh; ${ }^{2}$ Department of Food and \\ Nutrition, Home Economics College, Dhaka, Bangladesh.
}

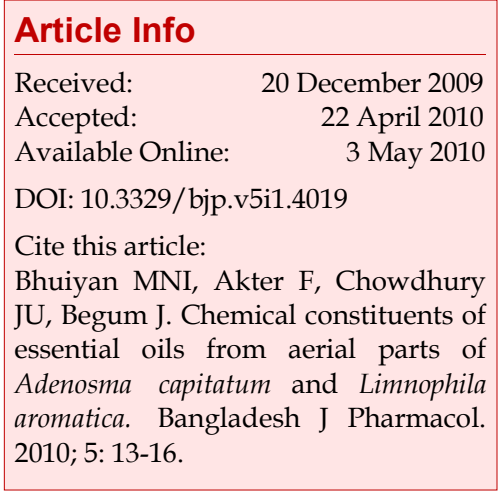

\begin{abstract}
The essential oils were isolated by hydrodistillation from the aerial parts of Adenosma capitatum and Limnophila aromatica and were analyzed by gas chromatography mass spectrometry (GC-MS). Forty six and thirty components were identified, representing 98.8 and $99.3 \%$ of the total oils respectively. Oil of $A$. capitatum rich in limonene $(24.7 \%)$, fenchone $(21.6 \%)$ and 2-carene $(17.6 \%)$. On the other hand, L. aromatica rich in Z-ocimene $(39.2 \%)$, terpinolene $(17.2 \%)$ and camphor $(12.9 \%)$.
\end{abstract}

\section{Introduction}

Adenosma capitatum (Bentham) Bentham ex Hance. belongs to the family Scrophulariaceae is a medicinal herb available throughout the world (Hooker, 1885). The anti-oxidant activity of $A$. capitatum was evaluated through its inhibiting ability in peroxidation lipid in cell culture. This result is valid for next research on chemical and bioassay based on its anti-oxidant competency (Huong and Bao, 2004). Ji and Pu (1985) reported that the main components in the $A$. indianum are $\alpha$-pinene, $\beta$ -pinene, limonene, p-cymene, 1,4-cineol, linalool, fenchone, o-methylanisole and 8-guaiene.

Limnophila aromatica (Lamk.) Merr. (Syn. Limnophila chinensis var. aromatica) also belongs to the same family Scrophulariaceae is native to Southeast Asia used as a spice and medicinal herb (Philcox, 1970). It is used in Vietnamese cuisine and also cultivated for use as an aquarium plant. The plant was introduced to North America in the 1970s due to Vietnamese immigration following the Vietnam War. L. aromatica has a flavor and aroma reminiscent of both lemon and cumin. Seve- ral species of Limnophila are found in silent waters Southeast Asia; some of them are common aquarium plants in the West. Rich soups of that kind are commonly eaten as a full meal in South East Asia. In Vietnam, they are typically served not with rice but with fresh French white bread (Kuebel and Tucker, 1988). In Asia, it is employed to treat many ailments. In China, it is used for the treatment of intoxication and pain. In Indochina, to treat wounds, in Malaysia, chiefly as a poultice on sore legs, but also to promote appetite and as an expectorant to clear mucus from the respiratory tract and to treat fever, and in Indonesia, as an antiseptic or cleanser for worms. The plant is also used in Asia for menstrual problems, wounds, dysentery, fever, elephantiasis and indigestion (Yamazaki, 1985). The previous report on the oil of this species found d-limonene and d-perillaldehyde from Formosa (Fujita and Yamashita, 1942). The leaves contain about $0.1 \%$ essential oil, whose main component is limonene. Among the other constituents identified in the oil are perillaldehyde, $\quad \alpha$-pinene, $\beta$-pinene, $(E)$ - $\beta$-ocimene, $(Z)-\beta$ ocimene, 1-octen-3-ol, cis-limonene oxide, trans-limo- 
nene oxide, linalool, bornyl acetate, (Z)- $\beta$-farnesene, $a$ humulene, a-terpineol, borneol, caranyl acetate, perillyl acetate, trans-shisool and an unusual monoterpenoid ketone, cis-4-caranone and trans-4-caranone (Tucker et al., 2002). My-Linh et. al. (2004) reported that uncommon 8-oxygenated flavonoids found from $L$. aromatica. Regarding A. capitatum and L. aromatica, essential oils, no work is available in our country. So, the work has been undertaken to study the chemical components of essential oils obtained from aerial parts of A. capitatum and L. aromatica grown in Bangladesh respectively.

\section{Materials and Methods}

\section{Plant material}

Fresh aerial parts of A. capitatum and L. aromatica were collected from the plants grown in the campus of BCSIR Laboratory, Chittagong during June 2007. Two-voucher specimens (Y-463 and Y-464) were deposited in the herbarium of BCSIR Laboratory, Chittagong.

\section{Extraction of essential oil}

Both aerial parts were harvested and air-dried for about one week. The oils were obtained by hydrodistillation for 4 hours in a Clevenger-type apparatus (Clevenger, 1928; Bhuiyan et al., 2009). The oil yields (calculated per weight of dried material) were $1.1 \%$ for $A$. capitatum and $1.0 \%$ for L. aromatica. The oil samples were stored in air-tight containers after drying them over anhydrous sodium sulfate for GC-MS analysis.

\section{GC-MS analysis}

The essential oil from aerial parts of $A$. capitatum and $L$. aromatica were analyzed by GC-MS electron impact ionization (EI) method on GC-17A gas chromatograph (Shimadzu) coupled to a GC-MS QP 5050A mass spectrometer (Shimadzu); fused silica capillary column (30 $\mathrm{m} \times 0.25 \mathrm{~mm} ; 0.25 \mathrm{~mm}$ film thick-ness), coated with DB5 (J \& W); column temperature $100^{\circ} \mathrm{C}(2 \mathrm{~min})$ to $250^{\circ} \mathrm{C}$ at the rate of $3^{\circ} \mathrm{C} / \mathrm{min}$; carrier gas, helium at constant pressure of $90 \mathrm{Kpa}$. Acquisition parameters full scan; scan range 40-350 amu.

\section{Identification of the compounds}

Compound identification was done by comparing the NIST library data of the peaks. Percentage composition was computed from GC peak areas on DB-5 column.

\section{Results and Discussion}

The essential oils from the aerial parts of A. capitatum and L. aromatica are presented with chemical constituents in Table I. A. capitatum oil contains 46 constituents of which the major is limonene $(24.7 \%)$. Other notable constituents are fenchone $(21.6 \%)$, 2carene (17.6\%), Z-octahydro-7a-methyl-1H-indene-1one $(14.3 \%)$, y-terpinene $(3.0 \%), \beta$-bisabolene $(2.8 \%)$, fenchyl alcohol $(2.1 \%)$, phytol $(1.9 \%)$, a-caryophyllene $(1.6 \%)$, caryophyllene $(1.1 \%)$ and 2-cyclohexen-1-one, 3methyl-6-(1-methyle ethelidene (1.0\%). According to GC-MS analysis under the conditions described above, Z-ocimene was detected as the main component (39.2\%) of this essential oil of L. aromatica. The remaining constituents are terpinolene $(17.2 \%)$, camphor $(12.9 \%), b$ -myrcene $(9.5 \%)$, limonene $(3.8 \%)$, caryophyllene (3.1\%), L-caryophyllene $(2.9 \%)$, a-pinene $(2.4 \%)$ and bfarnesene $(1.4 \%)$. The study reveals that composition of two oils differs from the earlier reports published in the literature and may, therefore be treated as different chemotypes (Ji and Pu, 1985; Fujita and Yamashita, 1942; Tucker et al., 2002). On the basis of above fact it may be concluded that A. capitatum and L. aromatica, growing widely in Bangladesh, may be utilized as a source for the isolation of natural limonene and ocimene respectively. Limonene is common in cosmetic products, used in food manufacturing and some medicines, e.g., bitter alkaloids, as a flavoring; it is also used as botanical insecticide. It is added to cleaning products such as hand cleansers to give a lemon-orange fragrance. As it is combustible, limonene has also been considered as a biofuel. In perhaps its most exciting application, limonene is useful for recycling polystyrene. In the 1990s, researchers at Sony discovered that limonene dissolves polystyrene, which can be recovered after boiling off the limonene (Mann et al., 1994). Besides, it is worth noting that the oil of $A$. capitatum and L. aromatica have been reported to be used in folk medicine in the treatment of menstrual problems, rheumatism, wounds, dysentery, fever, elephantiasis and indigestion.

\section{References}

Bhuiyan MNI, Chowdhury JU, Begum J. Chemical investigation of the leaf and rhizome essential oils of Zingiber zerumbet (L.) Smith from Bangladesh. Bangladesh J Pharmacol. 2009; 4: 9-12.

Clevenger JF. Apparatus for determination of volatile oil. J Am Pharm Assoc. 1928; 17: 346-49.

Fujita Y, Yamashita T. The essential oils of the southern Asiatic plants. III. Essential oils of Limonphila aromatica in Formosa. J Chem Soc Japan. 1942; 63: 995-98.

Hooker JD. Flora of British India. Vol. IV. L. Reeve and Co., Ltd., 1885, pp 263-64.

Huong HT, Bao HV. Contribution to the study on anti- oxidative properties of Adenosma capitatum Benth in Vietnam. TC Dugc Hoc. 2004; 10: 14-16.

Ji X, Pu Q. Studies on the components of the essential oil from 


\section{Table I}

\begin{tabular}{|c|c|c|c|c|}
\hline SN. & Name of constituents in A, capitatum & $\%$ & Name of constituents in L, aromatica & $\%$ \\
\hline 1 & $\mathrm{\gamma}$-Terpinene & 3.0 & Triethyl carbinol & 0.4 \\
\hline 2 & a-Thujene & 0.1 & Benzene & 0.3 \\
\hline 3 & a-Pinene & 0.5 & 2,4-Pentanedione & 0.1 \\
\hline 4 & d-Camphene & 0.8 & 3-Hexan-2-one & 0.1 \\
\hline 5 & Thujene & 0.1 & 5-N onenol-5-methyl & 0.5 \\
\hline 6 & $\beta$-Pinene & 0.1 & a-Pinene & 2.4 \\
\hline 7 & 1-Octen-3-op & 0.2 & Camphene & 0.3 \\
\hline 8 & 3-Octanone & 0.1 & 1-Octen-3-ol & 0.7 \\
\hline 9 & $\beta$-Myrcene & 0.2 & Sabinene & 0.5 \\
\hline 10 & 3-Carene & 0.3 & $\beta$-Myrcene & 9.5 \\
\hline 11 & 2-Carene & 17.6 & 2-Carene & 0.5 \\
\hline 12 & Benzene-1-methyl-4-(1-methylethyl) & 0.2 & m-Mymene & 0.2 \\
\hline 13 & Limonene & 24.7 & Limonene & 3.8 \\
\hline 14 & Z-Ocimene & 1.2 & Z-Ocimene & 39.2 \\
\hline 15 & Fenchone & 21.6 & g-Terpinene & 0.3 \\
\hline 16 & Linalool & 0.1 & Terpinolene & 17.2 \\
\hline 17 & 1,3,8-p-Menthatriene & 0.2 & $\begin{array}{l}\text { Acetic acid, tricyclo }[4.4 .0 .0(3,8)] \text { dec-9-en-4- } \\
\text { yl ester }\end{array}$ & 0.1 \\
\hline 18 & Fenchyl alcohol & 2.1 & Linalool & 0.8 \\
\hline 19 & $\begin{array}{l}\text { Bicyclo (3.2.1) oct-2-ene,3-methyl-4- } \\
\text { methylene }\end{array}$ & 0.5 & 3-Cyclohexene-1-carboxaldehyde & 0.6 \\
\hline 20 & Carveol & 0.3 & (-) Camphor & 12.9 \\
\hline 21 & Citral & 0.1 & p-Cymen-8-ol & 0.3 \\
\hline 22 & p-Cymen-8-ol & 0.1 & $\begin{array}{l}\text { 1,3-Cyclohexadiene-1-methanol, 4-(1- } \\
\text { methylethyl)- }\end{array}$ & 0.4 \\
\hline 23 & $\beta$-Terpinyl acetate & 0.2 & Caryophyllene & 3.1 \\
\hline 24 & 2-Isopropyl benzaldehyle & 0.2 & $\beta$-Farnesene & 1.4 \\
\hline 25 & Carveol & 0.3 & L-Caryophyllene & 2.9 \\
\hline 26 & $\begin{array}{l}\text { 2-Cyclohexen-1-one, 2-methyl-5-(1- meth- } \\
\text { ylethenyl) }\end{array}$ & 0.1 & Demethoxy-ageratochromene & 0.3 \\
\hline 27 & $\beta$-Phenethyl acetate & 0.1 & Caryophyllene oxide & 0.7 \\
\hline 28 & 3-Dodecyne & 0.1 & $\begin{array}{l}\text { 12-Oxabicyclo [9.1.0] dodeca-3,7-diene, } \\
\text { 1,5,5,8- tetramethyl }\end{array}$ & 0.4 \\
\hline 29 & $\begin{array}{l}\text { 2-Cyclohexen-1-one, 3-methyl-6-(1-methyle } \\
\text { ethelidene) }\end{array}$ & 1.0 & $\begin{array}{l}\text { 2,6,10-Cycloundecatriene-1-one, 2,6,9,9- } \\
\text { tetramethyl }\end{array}$ & 0.2 \\
\hline 30 & Eugenol & 0.1 & Caryophyllene & 0.2 \\
\hline 31 & Z-Octahydro-7 a-methyl-1-H-indene-1-one & 14.3 & & \\
\hline 32 & $\beta$-Elemene & 0.1 & & \\
\hline 33 & Caryophyllene & 1.1 & & \\
\hline 34 & a-Caryophyllene & 1.6 & & \\
\hline 35 & Demethyoxyageratocromene & 0.0 & & \\
\hline 36 & a-Bergamotene & 0.1 & & \\
\hline 37 & Patchoulene & 0.1 & & \\
\hline 38 & a-Farnesene & 0.2 & & \\
\hline 39 & $\beta$-Bisabolene & 2.8 & & \\
\hline 40 & !H-Benzene $(4,5)$ furo 3,2$)$ indole & 0.1 & & \\
\hline
\end{tabular}




\begin{tabular}{|c|c|c|c|c|}
\hline \multicolumn{5}{|c|}{ Table I } \\
\hline \multicolumn{5}{|c|}{ Constituents of essential oils from $A$. capitatum and L. aromatica (Continued) } \\
\hline SN. & Name of constituents in A, capitatum & $\%$ & Name of constituents in L, aromatica & $\%$ \\
\hline 41 & $\beta$-Sesquiphellandrene & 0.2 & & \\
\hline 42 & 1,5-Dodecadiene & 0.1 & & \\
\hline 43 & (E)-3-Hexenyl phenyl acetate & 0.3 & & \\
\hline 44 & $\begin{array}{l}\text { 2H-Indene,1-ethylidene octahydro-7a- me- } \\
\text { thyl,-cis }\end{array}$ & 0.1 & & \\
\hline 45 & 3-Pinanone & 0.9 & & \\
\hline 46 & Phytol & 1.9 & & \\
\hline
\end{tabular}

Adenosma indianum (Lour.) Merr. Zhlwuxue Bao. 1985; 27: 80 -83 .

Kuebel KR, Tucker AO. Vietnamese culinary herbs in the United States. Econ Bot. 1988; 42: 413-19.

Mann J, Davidson RS, Hobbs JB, Banthorpe DV, Harborne JB. Natural Products. Harlow, UK, Addison Wesley Longman Ltd., 1994, pp 308-09.

My-Linh B, Renee JG, Nigel CV, Geoffrey CK, Hung T, Quynh$\mathrm{Cu}$ KN. Uncommon 8-oxygenated flavonoids from Limnophila aromatica (Scrophulariaceae). Biochem
Systematics Ecol. 2004; 32: 943-47.

Philcox D. A taxonomic revision of the genus Limnophila. Br. (Scrophulariaceae). Kew Bull. 1970; 24: 101-70.

Tucker AO, Maciarello MJ, Hendi M, Wheeler KA. Volatile leaf and stem oil of commercial Limnophila chinensis (Osb.) Merrill ssp aromatica (Lam.) Yamazaki (Scrophulariaceae). J Essent Oil Res. 2002; 14: 228-29.

Yamazaki T. A revision of the genera Limnophila and Torenia from Indochina. J Fac Sci Univ Tokyo. 1985; 13: 575-625. 